\title{
ЭФФЕКТИВНОСТЬ ИСПОЛЬЗОВАНИЯ ФИНАНСОВЫХ СРЕДСТВ ОРГАНИЗАЦИЯМИ, ПРЕДОСТАВЛЯЮЩИМИ УСЛУГИ ПО РЕАБИЛИТАЦИИ ИНВАЛИДОВ И ДЕТЕЙ-ИНВАЛИДОВ
}

\author{
(c) 2019 Максимова Маргарита Николаевна \\ доктор экономических наук, доцент, заведующая кафедрой экономической теории \\ и социальной работы; декан факультета социальной работы и высшего сестринского образования \\ Казанский государственный медицинский университет \\ Министерства здравоохранения Российской Федерации, Казань \\ E-mail: soc90@mail.ru
}

(c) 2019 Максимов Дмитрий Сергеевич

ассистент кафедры экономической теории и социальной работы

Казанский государственный медицинский университет

Министерства здравоохранения Российской Федерации, Казань

\section{(c) 2019 Гинсбург Мария Владимировна}

кандидат экономических наук, доцент кафедры экономической теории и социальной работы

Казанский государственный медицинский университет

Министерства здравоохранения Российской Федерации, Казань

E-mail: mvginsburg@bk.ru

Проведен анализ эффективности использования бюджетных средств, выделенных в 2015-2018 годах на обеспечение деятельности социальных учреждений, предоставляющих услуги по реабилитации и абилитации инвалидов, детей-инвалидов в целях оценки результативности деятельности центров реабилитации инвалидов. По результатам анализа эффективности сделаны выводы, предложения и рекомендации.

Ключевые слова: услуги по реабилитации и абилитации инвалидов; эффективность использования бюджетных средств; финансирование центров реабилитации инвалидов.

Одна из важнейших задач системы социальной защиты граждан России - социальная поддержка, реабилитация и абилитация инвалидов. Государственная социальная политика в отношении граждан-инвалидов - это индикатор экономического и социального развития общества в целом, показатель толерантности общества, социального государства. Государственная социальная политика определяется необходимостью обеспечения возможностей участия в жизни общества, социальной и правовой защищённостью, поддержанием достойного жизненного уровня, созданием условий для трудовой деятельности для инвалидов наравне с другими гражданами.

Созданная в Республике Татарстан (далее РТ) система государственных реабилитационных учреждений обеспечивает одно из основных условий осуществления реабилитации и абилитации инвалидов. В 2018 году система включала 19 реабилитационных центров для инвалидов, в том числе 13 реабилитационных центров для детей и подростков с ограниченными возможностями, 6 центров реабилитации инвалидов и государственное бюджетное учреждение «Республиканский центр социальной реабилитации слепых и слабовидящих». Работа всех центров реабилитации организована по межрайонному принципу [5]. Социальные услуги предоставляются в стационарной и полустационарной формах социального обслуживания. В 2018 году (по состоянию на 16.11.2018 года) в государственных реабилитационных учреждениях Министерства труда, занятости и социальной защиты Республики Татарстан (далее - МТ3 и СЗ РТ) прошли реабилитацию 7400 детей-инвалидов, 6431 инвалидов.

Для оценки результативности деятельности республиканских центров реабилитации и абилитации инвалидов был проведён анализ эффективности использования бюджетных средств, которые выделены в 2015-2017 годах и 
в начале 2018 года на обеспечение деятельности центров, предоставляющих услуги по реабилитации и абилитации инвалидов и детей-инвалидов [5]. По результатам анализа были сделаны выводы, предложения и рекомендации.

Цели анализа эффективности:

- оценить эффективность деятельности центров при использовании государственных финансовых средств, выделенных из бюджета на предоставление услуг по реабилитации инвалидов и детей-инвалидов;

- определить степень достижения значений целевых индикаторов и показателей, установленных государственной программой «Социальная поддержка граждан Республики Татарстан» на 2014-2025 годы» [1] и порядками предоставления социальных услуг [2, 3, 4].

Предмет анализа эффективности:

- государственные бюджетные средства, выделенные на обеспечение деятельности центров, предоставляющих услуги по реабилитации и абилитации инвалидов и детей-инвалидов;

- нормативные и правовые, распорядительные документы, регламентирующие деятельность учреждений, предоставляющих услуги по реабилитации и абилитации инвалидов и детей-инвалидов; финансовые и иные документы, обосновывающие и подтверждающие использование средств бюджета РТ;

- деятельность центров, предоставляющих услуги по реабилитации и абилитации инвалидов и детей-инвалидов.

Нормативно-правовое регулирование деятельности учреждений по реализации мероприятий по реабилитации инвалидов и детей-инвалидов осуществляется в соответствии с Конвенцией о правах инвалидов, Федеральными законами от 24 ноября 1995 года № 181-Ф3 «О социальной защите инвалидов в Российской Федерации», от 28 декабря 2013 года № 442-Ф3 «Об основах социального обслуживания граждан в Российской Федерации» и подзаконными нормативными правовыми документами $[2,3,4]$.

Постановлением Кабинета Министров Республики Татарстан от 23.12.2013 № 1023 утверждена Государственная программа «Социальная поддержка граждан Республики Татарстан на 2014-2025 годы» (далее - Программа» [1]), подпрограммы которой содержат комплекс мероприятий, способствующих повышению эффективности и результативности деятельности организаций, предоставляющих услуги по реабилитации инвалидов и детей-инвалидов. Постановлениями Кабинета Министров Республики Татарстан от 31.12.2014 №№ 1100 и 1101 утверждены Порядок предоставления социальных услуг поставщиками социальных услуг в стационарной (и полустационарной) форме социального обслуживания в РТ [3] и Порядок предоставления социальных услуг в стационарной (и полустационарной) форме социального обслуживания в центрах реабилитации инвалидов, реабилитационных центрах для детей и подростков с ограниченными возможностями [4], Порядок предоставления социальных услуг в полустационарной форме социального обслуживания в центре социальной реабилитации слепых и слабовидящих.

Центры, кроме государственных бюджетных учреждений, созданы в соответствии с Федеральным законом «Об автономных учреждениях» от 3 ноября 2006 года № 174-ФЗ и на основании постановлений Кабинета Министров Республики Татарстан. Учреждения осуществляют свою деятельность на основании Уставов, утверждённых приказами МТЗ и С3 РТ и согласованных с распоряжениями Министерства земельных и имущественных отношений РТ. Все учреждения - юридические лица, имеют печать со своим наименованием и другие необходимые для осуществления своей деятельности штампы, бланки и другие реквизиты. Полномочия учредителя учреждений от имени РТ осуществляет МТЗ и СЗ РТ.

Предмет деятельности центров: предоставление услуг в сфере социального обслуживания в соответствии с законодательством РФ и РТ.

Основная цель деятельности учреждений улучшение условий жизнедеятельности граждан, признанных нуждающимися в социальном обслуживании, и (или) расширении их возможностей самостоятельно обеспечивать свои основные жизненные потребности. Для указанной цели учреждения осуществляют следующие виды деятельности: предоставление в полустационарной (стационарной) форме социального обслуживания инвалидам и детям-инвалидам, признанным нуждающимися в социальном обслуживании, а также гражданам, признанным нуждающимися в социальном обслуживании в связи с наличием в семье нуждающегося в постоянном постороннем уходе инвалида, следующих услуг: социально-бытовые, социально-медицинские, социально-психологические, социаль- 
но-педагогические услуги, социально-трудовые услуги, социально-правовые услуги, услуги в целях повышения коммуникативного потенциала получателей социальных услуг, имеющих ограничения жизнедеятельности [2, 3, 4]. На основании лицензий, выданных Министерством образования и науки РТ, ряд центров для детей-инвалидов осуществляют образовательную деятельность.

Центры неравномерно размещены на территории РТ: центры реабилитации для детей расположены на территории восьми муниципальных районов РТ и в г. Казани ив г. Набережные Челны, центры реабилитации для взрослых - на территории четырёх муниципальных районов и в г. Казани. Поэтому возникают риски недоступности услуг по реабилитации и абилитации инвалидов, проживающих в большинстве муниципальных районов.

Показателями, характеризующими качество государственной услуги по предоставлению учреждением в 2015-2017 годы социальных услуг, являются:

- доля получателей социальных услуг от общего числа таковых, находящихся на социальном обслуживании в организации;

- количество нарушений санитарного законодательства в отчётном году, выявленных при проведении проверок;

- удовлетворённость получателей социальных услуг в оказанных социальных услугах;

- укомплектование организации специалистами, оказывающими социальные услуги;

- повышение качества социальных услуг и эффективности их оказания (определяется исходя из мероприятий, направленных на совершенствование деятельности организации при предоставлении социального обслуживания);

- доступность получения социальных услуг.

Отчётные данные за 2015-2017 годы и период 2018 года выявили недовыполнение в центрах показателей по объёмам и качеству оказанных услуг. К причинам отличий фактических значений от плановых относятся [5]:

- неполная укомплектованность центров специалистами, оказывающими социальные услуги, в связи с отсутствием специалистов необходимой квалификации, сокращением вакантных должностей и изменением штатного расписания;

- переход на новые условия предоставления услуг привёл к значительному спаду численно- сти инвалидов, поступающих на обслуживание в 2015 году, на 22\% по сравнению с 2014 годом (изменился пакет документов, предоставляемых инвалидами для обслуживания, теперь необходимо предоставлять сведения-документы о доходах; изменился порядок взимания частичной оплаты за оказанные социальные услуги; увеличилась сумма оплаты для некоторых категорий обслуживаемых);

- снижение посещаемости центров в праздничные дни, в летний период.

В Центре реабилитации слепых и слабовидящих в 2017 году невыполнение государственного задания составило 35\%. А допустимые (возможные) отклонения от установленных показателей качества государственной услуги, в пределах которых государственное задание считается выполненным (процентов), установлено государственным заданием на 2017 год в размере 10\% [5].

Основанием для решения вопроса о предоставлении социального обслуживания в соответствии с Порядком предоставления услуг является поданное в письменной или электронной форме заявление гражданина или его законного представителя о предоставлении социального обслуживания, составленное по форме, утверждаемой приказом Минтруда России, либо обращение в его интересах иных граждан, государственных органов, органов местного самоуправления, общественных объединений непосредственно в орган государственной власти PT, уполномоченный на признание граждан нуждающимися в социальном обслуживании, и составление индивидуальной программы предоставления социальных услуг, либо переданное заявление или обращение в рамках межведомственного информационного взаимодействия [2, 3].

Предоставление социальных услуг в полустационарной форме осуществляется на основании договора о предоставлении социальных услуг, заключаемого между поставщиком социальных услуг и гражданином (его законным представителем), при представлении соответствующих документов в течение суток с даты представления индивидуальной программы предоставления социальных услуг поставщику социальных услуг [2, 3].

В случае превышения спроса на получение социальных услуг над возможностью их оказания приём получателей социальных услуг на 
социальное обслуживание осуществляется в соответствии с очерёдностью, учитываемой поставщиком социальных услуг (очерёдность на оказание услуг по реабилитации за анализируемый период представлена в таблице) [5].

Данные таблицы характеризуют ежегодное снижение численности граждан, ожидающих оказание реабилитационных услуг.

Постановлением Кабинета Министров Республики Татарстан от 31.12.2015 № 1044 «О порядке формирования государственного задания на оказание государственных услуг (выполнение работ) в отношении государственных учреждений и финансового обеспечения выполнения государственного задания» (далее - постановление № 1044) утверждена форма отчёта о выполнении государственного задания, в структуру которого входит [4]:

Часть 1. Сведения об оказываемых государственных услугах, содержащие сведения о фактическом достижении показателей, характеризующих объём и (или) качество государственной услуги, в том числе:

- показатель, характеризующий содержание государственной услуги;

- показатель, характеризующий условия (формы) оказания государственной услуги;

- допустимое отклонение;

- отклонение, превышающее допустимое отклонение;

- причина отклонения.

Часть 2. Сведения о выполняемых работах, содержащие сведения о фактическом достижении показателей, характеризующих объём и (или) качество государственной услуги.

Центры представляют отчёты о выполнении государственного задания за каждый год.

Согласно п. 4 части 1 постановления № 1044 «...государственное задание и отчёт о выполнении государственного задания ... подписываются усиленной квалифицированной электронной подписью исполнительного органа государственной власти Республики Татарстан, осуществляющего функции и полномочия учре- дителя государственного бюджетного или автономного учреждения» [4].

Сведения о фактическом достижении показателей, характеризующих объём и качество услуг отражены в отчётах центров. При этом в отчётах за 2015-2016 годы отсутствуют данные об условиях (формах) оказания государственной услуги, допустимом отклонении, отклонении, превышающем допустимое отклонение; не во всех отчётах указаны причины отклонения от плановых показателей [5].

Финансирование деятельности центров реабилитации инвалидов осуществляется из бюджета РТ в рамках государственных заданий, также выделяются субсидии на иные цели.

В соответствии с пунктом 30 постановления № 1044 финансовое обеспечение выполнения государственного задания осуществляется в пределах бюджетных ассигнований, предусмотренных бюджетом Республики Татарстан на указанные цели [4].

Практика свидетельствует о ежегодном увеличении объёмов финансирования. На выполнение государственных заданий центрам реабилитации в 2015-2017 годах направлено 1123244,1 тыс. руб., в том числе в 2015 году $-357380,9$ тыс. руб., в 2016 году - 363416,6 тыс. руб., в 2017 году - 402446,6 тыс. руб. За 9 месяцев 2018 года 280394,5 тыс. руб. За анализируемый период рост составил 12,6\%. А кассовое исполнение по всем Центрам составило: в 2015 году - 96\%, в 2016 году - 98\%, в 2017 году - 95\% от объёма финансирования [5].

Анализ обоснованности объёма финансового обеспечения выполнения задания в части стоимости услуг содержания имущества и соблюдение финансовых нормативов затрат на одного получателя услуг показал следующее. Постановлением № 1044 с 01.01.2016 утверждено Положение о формировании государственного задания на оказание государственных услуг (выполнение работ) в отношении государственных учреждений и финансовом обеспечении выполнения государственного задания. Согласно

Таблица1. Очерёдность на оказание услуг по реабилитации за анализируемый период (человек) [5]

\begin{tabular}{|l|c|c|c|c|}
\hline \multicolumn{1}{|c|}{ Показатели } & На 01.01.2016 & На 01.01.2017 & На 01.01.2018 & На 16.11 .2018 \\
\hline $\begin{array}{l}\text { Очерёдность в центры } \\
\text { реабилитации, всего }\end{array}$ & 12332 & 12208 & 12088 & 10679 \\
\hline $\begin{array}{l}\text { в том числе: } \\
\text { взрослые инвалиды }\end{array}$ & 9422 & 9329 & 9236 & 7818 \\
\hline дети-инвалиды и дети с ОВ3 & 2910 & 2879 & 2852 & 2861 \\
\hline
\end{tabular}


Положению, нормативные затраты на оказание государственной услуги состоят из базовых нормативных [4]:

а) затрат, непосредственно связанных с оказанием государственной услуги;

б) затрат на общехозяйственные нужды на оказание государственной услуги.

В объём финансового обеспечения выполнения государственного задания включаются затраты на оплату налогов, в качестве объекта налогообложения по которым признаётся имущество учреждения.

Нормативные затраты и базовые нормативные затраты на содержание имущества, базовые нормативные затраты на оказание услуг и нормативное количество койко-мест в учреждении социального обслуживания Республики Татарстан устанавливается ежегодно на основании соответствующих постановлений Кабинета Министров Республики Татарстан.

На разницу в финансировании текущего финансового года корректируется объём финансирования в следующем году. При этом в случае перевыполнения $1 / 12$ установленного годового плана финансирование сверх плана не предусмотрено. Например, в РЦ «Здравушка» в соответствии со счетами-реестрами за 2015 год учреждение выполнило план государственного задания на 12778 койко-дней, однако по расчётам, установленным Министерством финансов РТ, государственное задание выполнено в размере 12354 койко-дня и соответственно объём финансового обеспечения составляет 14805,7 тыс. руб.

Фактически объём финансирования в 2015 году составил 14856,6 тыс. рублей, перефинансирование - 50,9 тыс. рублей. По решению Министерства финансов РТ (№ 24720-РГ от 09.12.2015 финансирование услуг в декабре 2015 года осуществлялось по плану, с последующей корректировкой объёма финансирования по фактическому исполнению государственного задания в 2016 году). В 2016 году был утверждён «усечённый» годовой план на выполнение государственного задания (11925 койко-дней) [5].

По счетам-реестрам за 2016 год план государственного задания центр выполнил на 12941 койко-день. А по расчётам, установленным Министерством финансов РТ, государственное задание выполнено в размере 11630 койко-дней и соответственно объём финансового обеспечения составляет 14459,3 тыс. руб.
Фактически государственное задание за 2016 год профинансировано на сумму 14459,6 тыс. рублей, или недофинансировано на 0,3 тыс. рублей (округление).

Такое финансирование объясняется тем, что в 2016 году согласно Регламенту межведомственного взаимодействия между Министерством финансов РТ и МТЗ и С3 РТ по вопросам финансового обеспечения расходов на выполнение государственного задания государственными организациями социального обслуживания РТ за счёт средств бюджета РТ на 2016 год (далее Регламент) было принято следующее решение: годовой план 11925 койко-дней разделить на 12 месяцев. Финансирование осуществлялось ежемесячно по представленным в МТ3 и С3 РТ счетам-реестрам за фактически выполненный объём государственных услуг за отчётный месяц, т.е. в случае невыполнения $1 / 12$ установленного плана учреждение финансировалось по факту, в случае перевыполнения 1/12 установленного плана финансирование сверх не осуществлялось [5].

В Центре реабилитации слепых и слабовидящих в 2015 году финансирование центра осуществлялось исходя из нормативных затрат ежемесячно в размере 1/12 от общего объёма выделенных средств на 2015 год. В соответствии c Регламентом финансирование центра осуществлялось ежемесячно в размере 1/12 от установленного плана, в случае перевыполнения 1/12 установленного годового плана финансирование сверх плана не осуществлялось [5].

Кроме финансирования государственного задания, центрам реабилитации выделяются субсидии на иные цели. Общий объём субсидий на иные цели за 2015-2017 годы составил 44472,5 тыс. рублей, за 9 месяцев 2018 года 30994тыс. рублей.

Проведённый анализ использования средств субсидий, выделенных Центрам на приобретение оборудования для оснащения автотранспорта, мебели и оборудования выявил, что не все средства использовались эффективно. Часть приобретённого имущества не используется, хранится на складе [5].

В центрах реабилитации имеются значительные объёмы неиспользуемых денежных средств. Так, в соответствии с отчётными данными общий остаток субсидий на госзадание на 01.01.2016 год составил 13231,8 тыс. руб., субсидий на иные цели - 5965,6 тыс. руб., оста- 
ток субсидий на госзадание на 01.01.2017 года 11084,1 тыс. руб., субсидии на иные цели - 560,4 тыс. руб., остаток субсидии на госзадание на 01.01.2018 года - 16649,4 тыс. руб., субсидии на иные цели - 1909,1 тыс. руб. Средства субсидий на госзадание в сумме 11084,1 тыс. рублей не используются более двух лет [5].

Таким образом, анализ свидетельствует о снижении дебиторской задолженности за анализируемый период в большинстве центров. В отдельных учреждениях произошло увеличение дебиторской задолженности, вызванное авансовыми платежами поставщикам товаров и услуг сверх фактической потребности. Кроме того, ежегодно отдельные центры увеличивали дебиторскую задолженность, осуществляя расходы будущих периодов: в результате оплаты расходов сверх произведённых начислений по платежам в ФСС; в результате оплаты расходов сверх произведённых начислений по платежам в бюджет, в том числе по земельному налогу, налогу на имущество, транспортному налогу, платежам в ПФР, в ФОМС [5].

В ряде центров не соблюдались нормативы расхода ГСМ при поездках; в путевых листах не содержалась информация о маршруте следования. Сложно определить служебный характер поездок на автомобилях в связи с отсутствием в путевых листах информации о месте отправления и назначения, предусмотренной типовой формой, утверждённой постановлением Госкомстата России от 28.11.1997 № 78. Поэтому, отсутствие сведений о пунктах следования автомобиля не позволяет судить о факте его использования сотрудником в служебных целях и не является достаточным основанием для подтверждения экономической обоснованности расходов на ГСМ. Не подтверждены соответствующими приказами на командирование сотрудников по фактам осуществления поездок на служебном автотранспорте за пределы г. Казани [5].

Кроме бюджетного формирования доходов центров реабилитации инвалидов, не связанных с выполнением государственного задания, а также использование указанных средств согласно уставу Центры вправе заниматься приносящей доход и иной не запрещённой действующим законодательством деятельностью, необходимой для достижения уставных целей, в том числе:

a) оказывать государственные услуги (работы), указанные при их предоставлении сверх государственного задания; б) услуги, не входящие в перечень государственных услуг, являющиеся дополнительными к государственным услугам, в пределах основных видов деятельности.

Анализ полученных центрами средств от приносящей доход деятельности показал, что общая сумма доходов центров реабилитации инвалидов, не связанных с выполнением государственного задания, существенно не изменилась и составила: в 2015 году - 16138,1 тыс. руб., в 2016 голу - 16124,4 тыс. руб., в 2017 году 17819 тыс. руб. Увеличилась по сравнению с 2015 годом на 10,4\% [5]. Источниками формирования доходов центров реабилитации являются средства от оказания платных услуг, средства благотворительной помощи, средства от возмещения арендаторами коммунальных услуг, доход от реализации автотранспорта, металлолома.

В 2018 году в рамках реализации федерального партийного проекта «Крепкая семья» финансировался проект «Сможем вместе», за счёт которого в реабилитационных центрах были оборудованы 26 кабинетов социальной адаптации, компьютерные классы, мастерские. В 7 центрах благоустроили территории. Привлечено 20.5 млн.рублей от благотворителей.

Наибольшая доля расходов, полученных от иной приносящей доход деятельности центров, приходится на приобретение основных средств и материальных запасов, выплату заработной платы и прочие расходы. Однако в центрах не выполняется решение МТЗ и С3 РТ: не менее $75 \%$ доходов, поступающих от осуществления предпринимательской и иной приносящей доход деятельности, направлять на выплату заработной платы.

Наблюдается динамика изменения стоимости тарифов на платные услуги.

Результаты анализа показывают, что МТЗ и С3 РТ необходимо [5]:

1) разработать план мероприятий, направленных на повышение эффективности использования бюджетных средств, выделенных на обеспечение деятельности центров, предоставляющих услуги по реабилитации инвалидов и детей-инвалидов;

2) обратиться в Кабинет Министров Республики Татарстан с предложением внесения изменений в постановление Кабинета Министров Республики Татарстан от 31.12.2009 года № 915 «Об утверждении Положения о порядке расчёта нормативных затрат на оказание социальных 
услуг организаций социального обслуживания и подушевых нормативов финансирования социальных услуг, предоставляемых поставщиками социальных услуг в Республике Татарстан» в части обеспечения реабилитационных центров мягким инвентарём с учётом фактической потребности в зависимости от формы обслуживания, в частности в реабилитационных центрах с полустационарной формой социального обслуживания;

3) разработать и принять управленческое решение по невостребованному реабилитационными центрами государственному имуществу в целях его эффективного использования.

Учреждениям реабилитации и абилитации инвалидов:

1) осуществлять постоянный и качественный контроль за эффективным использованием выделенных средств, принять меры для снижения дебиторской задолженности, исключить об- разование невостребованных остатков средств;

2) провести анализ дебиторской задолженности, возникшей вследствие авансирования поставщиков товаров и услуг сверх установленных обязательств, по результатам которого принять меры к возврату средств, обеспечению своевременной поставки товаров, работ, услуг;

3) повысить внутренний финансовый контроль, личную ответственность каждого сотрудника центров;

4) не менее $75 \%$ доходов, поступающих от осуществления предпринимательской и иной приносящей доход деятельности, направлять на выплату заработной платы;

5) осуществлять достоверность, своевременность и полноту отражения результатов финансово-хозяйственной деятельности в бухгалтерской (финансовой), налоговой и иной отчётности.

\section{Библиографический список}

1. Государственная программа «Социальная поддержка граждан Республики Татарстан на 2014-2021 годы», утверждённая Постановлением Кабинета Министров Республики Татарстан от 23.12.2013 года № 1023.

2. Постановление Кабинета Министров Республики Татарстан от 31.12.2014 года № 1100 «Об утверждении порядка предоставления социальных услуг поставщиками социальных услуг в стационарной (и полустационарной) форме социального обслуживания в РТ».

3. Постановление Кабинета Министров Республики Татарстан от 31.12.2014 года № 1101 «Об утверждении Порядка предоставления социальных услуг в стационарной (и полустационарной) форме социального обслуживания в центрах реабилитации инвалидов, реабилитационных центрах для детей и подростков с ограниченными возможностями».

4. Постановление Кабинета Министров Республики Татарстан от 31.12.2015 года № 1044 «О порядке формирования государственного задания на оказание государственных услуг (выполнение работ) в отношении государственных учреждений и финансового обеспечения выполнения государственного задания» (с изменениями на 25 июня 2019 года).

5. Постановление Комитета Государственного Совета Республики Татарстан по образованию, культуре, науке и национальным вопросам «Об отчёте Счётной палаты Республики Татарстан о результатах аудита эффективности использования средств бюджета Республики Татарстан, выделенных в 2015-2017 годах и истекшем периоде 2018 года на обеспечение деятельности организаций, предоставляющих услуги по реабилитации инвалидов и детей-инвалидов». 